\author{
Aleksander OLEJNIK ${ }^{1}$ \\ Krzysztof FALKOWSKI ${ }^{2}$ \\ Maciej HENZEL ${ }^{3}$
}

\title{
MOŻLIWOŚCI BADAWCZE ZAWIESZEŃ MAGNETYCZNYCH W LABORATORIUM BADAŃ NAPĘDÓW LOTNICZYCH WAT
}

\begin{abstract}
W pracy zostało opisane Laboratorium Badań Napędów Lotniczych w Wojskowej Akademii Technicznej, które powstało w wyniku realizacji projektu POIG.02.02.00-14-022/09 Programu Operacyjnego Innowacyjna Gospodarka. W laboratorium powstała m.in. Pracowania Zawieszeń Magnetycznych, w której są prowadzone unikatowe w skali kraju i Unii Europejskiej numeryczne oraz doświadczalne badania nad zawieszeniami magnetycznymi, ich optymalizacją, sterowaniem, zasilaniem itp. Ze względu na bardzo dobre właściwości funkcjonalne zawieszeń magnetycznych, np. takich jak praca w bardzo niskich temperaturach i wysokiej próżni, rozwiązania tego typu znajdują zastosowanie w technologiach kosmicznych. Obecnie można zaobserwować bardzo dynamiczny rozwój systemów lewitacji magnetycznej i ich systematyczne wykorzystanie w różnych aplikacjach. Działalność laboratorium jest nakierowana na rozwiązywanie problemów napędów lotniczych i istotnie przyczyni się do rozwiązywania problemów eksploatacyjnych, umożliwi modernizację testowanych konstrukcji, jak również projektowanie nowych.
\end{abstract}

Słowa kluczowe: zawieszenia magnetyczne, napędy lotnicze, optymalizacja, sterowanie

\section{Wprowadzenie}

W Wojskowej Akademii Technicznej i na Politechnice Warszawskiej jest realizowany projekt POIG.02.02.00-14-022/09 pt. ,Modernizacja i budowa nowej infrastruktury badawczej Wojskowej Akademii Technicznej i Politechniki Warszawskiej na potrzeby wspólnych numeryczno-doświadczalnych badań lot-

\footnotetext{
${ }^{1}$ Aleksander Olejnik, Wojskowa Akademia Techniczna, ul. S. Kaliskiego 2, 00-908 Warszawa, e-mail: aleksander.olejnik@wat.edu.pl

${ }^{2}$ Krzysztof Falkowski, Wojskowa Akademia Techniczna, ul. S. Kaliskiego 2, 00-908 Warszawa, e-mail: krzysztof.falkowski@wat.edu.pl

${ }^{3}$ Autor do korespondencji/corresponding author: Maciej Henzel, Wojskowa Akademia Techniczna, ul. S. Kaliskiego 2, 00-908 Warszawa, tel.: (22) 6839858, e-mail: maciej.henzel@ wat.edu.pl
} 
niczych silników turbinowych”. Bezpośrednim celem projektu jest modernizacja i budowa nowej zintegrowanej infrastruktury badawczej z zakresu badań silników lotniczych oraz wzmocnienie potencjału badawczego współpracujących ze sobą Laboratorium Badań Napędów Lotniczych WAT oraz Laboratorium Aerodynamiki Turbin Lotniczych i Spalania Politechniki Warszawskiej. W obszarze badań przepływu w turbinowych silnikach odrzutowych będą prowadzone prace naukowo-badawcze dotyczące zagadnień aerodynamiki kanałów przepływowych turbin, a także kanałów międzyłopatkowych wieńców dyszowych i wirnikowych, aerodynamiki oraz aerosprężystości pojedynczych łopatek dyszowych i wirnikowych oraz ich palisad $\mathrm{z}$ wykorzystaniem charakterystyk otrzymanych $\mathrm{z}$ badań wagowych modeli w tunelach aerodynamicznych oraz obliczeń numerycznych. Oprócz wyposażenia i oprogramowania jest przewidziany zakup do dyspozycji laboratorium m.in. zmodernizowanych $\mathrm{w}$ ramach projektu tuneli aerodynamicznych małych i dużych prędkości. W zakresie statyki i dynamiki lotniczych zespołów napędowych Laboratorium będzie się zajmować modelowaniem numerycznym zespołów wirnikowych i ich elementów, np. badaniem zjawiska flatteru łopatek. Wyznaczane będą właściwości dynamiczne konstrukcji na podstawie modeli numerycznych, a wyniki będą porównywane z wynikami badań eksperymentalnych. W zakresie pomiarów cieplnych będą badane wielkości gazodynamiczne w układach przepływowych oraz właściwości cieplne materiałów stosowanych do budowy turbinowych silników lotniczych i energetycznych turbin gazowych. Wyposażenie będzie obejmować przyrządy do pomiaru dyfuzyjności cieplnej, przewodności cieplnej, ciepła właściwego oraz rozszerzalności cieplnej materiałów na potrzeby innych badań prowadzonych w Laboratorium. W zakresie aktywnych zawieszeń magnetycznych Laboratorium będzie prowadzić unikatowe w skali kraju numeryczne oraz doświadczalne badania nad opracowywaniem pasywnych i aktywnych zawieszeń magnetycznych, ich optymalizacją, sterowaniem nimi, zasilaniem itp. Laboratorium zajmie się także dostosowaniem łożysk magnetycznych oraz ich osprzętu dla konkretnych aplikacji w lotniczych silnikach turbinowych. Obecnie są prowadzone m.in. prace nad bezłożyskowymi maszynami elektrycznymi (silniki, generatory, prądnico-rozruszniki).

Laboratoria WAT i Politechniki Warszawskiej będą także służyć podnoszeniu kwalifikacji kadry naukowo-badawczej i doktorantów. W laboratoriach przewiduje się również prowadzenie zajęć dydaktycznych oraz dyplomowych prac końcowych na studiach I i II stopnia.

\section{Pracownia zawieszeń magnetycznych}

Jednym z zespołów realizujących główny cel projektu jest utworzona w Laboratorium Pracownia Zawieszeń Magnetycznych. Pracownia ta prowadzi badania naukowe ukierunkowane na wykorzystanie zjawiska aktywnej i pasywnej lewitacji magnetycznej w technice lotniczej, których wyniki były publiko- 
wane na wielu konferencjach krajowych i zagranicznych $[1,2]$ oraz w czasopismach naukowych [3-5]. Obecnie można zaobserwować bardzo dynamiczny rozwój systemów lewitacji magnetycznej i ich systematyczne wykorzystanie w aplikacjach lotniczych i kosmicznych. Systemy łożysk magnetycznych są wykorzystywane w:

- silnikach turbinowych,

- lotniczych układach wykonawczych,

- bezłożyskowych napędach, generatorach, prądnico-rozrusznikach,

- systemach startu i lądowania, inercjalnym systemie sterowania i stabilizacji położenia w przestrzeni obiektów kosmicznych,

- kinetycznych akumulatorach energii umożliwiających zasilanie pojazdu kosmicznego przy wchodzeniu w cień Ziemi,

- aktywnych systemach zawieszeń magnetycznych do tłumienia, monitorowania, diagnozowania i sterowania drganiami,

- bezłożyskowych napędach liniowych i obrotowych (urządzeniach, w których łączy się zjawisko lewitacji magnetycznej i generowanie momentu obrotowego lub siły pociągowej),

- bezłożyskowych prądnico-rozrusznikach dla lotniczych silników turbinowych łączących funkcję łożyska, silnika elektrycznego i prądnicy,

- ciągach transportu magnetycznego umożliwiającego przenoszenie ładunków w warunkach braku grawitacji,

- wyrzutniach liniowych z lewitacją magnetyczną dla statków powietrznych i kosmicznych,

- inercjalnych przyrządach pomiarowych - giroskopach i przyspieszeniomierzach dla systemów nawigacyjnych o bardzo dużej precyzji pomiaru parametrów ruchu.

Ze względu na bardzo dobre właściwości funkcjonalne zawieszeń magnetycznych (praca w bardzo niskich temperaturach i wysokiej próżni) rozwiązania tego typu znajdują powszechne zastosowanie w technologiach kosmicznych [2]. $\mathrm{Na}$ rysunkach 1. i 2. są przedstawione przykłady konstrukcji wykonanych w WAT. Zespół badawczy realizuje projekty obejmujące wykonanie siłowników, zasilaczy, systemów sterowania i łożysk pomiarowych. Prowadzone są również prace mające na celu wykonanie bezłożyskowych maszyn i generatorów [2].

Obecnie zespół badawczy prowadzi prace nad zbudowaniem lotniczych układów wykonawczych z bezłożyskowymi napędami elektrycznymi i systemami łożyskowania silników lotniczych oraz pędników pojazdów podwodnych. Badane są nowe konstrukcje napędów elektrycznych dla lotniczych układów wykonawczych. Na rysunku 3. jest przedstawiony bezłożyskowy silnik elektryczny. Badaniom poddano silniki synchroniczne i asynchroniczne. Inną grupą badanych napędów elektrycznych są liniowe silniki elektryczne, które umożliwiają zamianę energii elektrycznej na ruch liniowy bez dodatkowych elementów i układów, jak to ma miejsce w układach wykonawczych z silnikami obrotowy- 

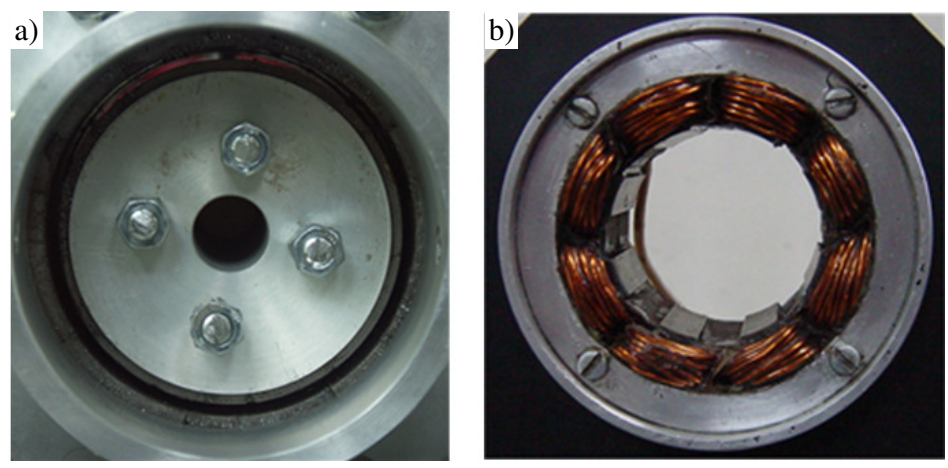

Rys. 1. Łożyska magnetyczne opracowane i wykonane w WAT: a) pasywne promieniowe, b) aktywne heteropolarne

Fig. 1. Magnetic suspensions developed and performed at the Military University of Technology, types: a) passive radial, b) active heteropolar
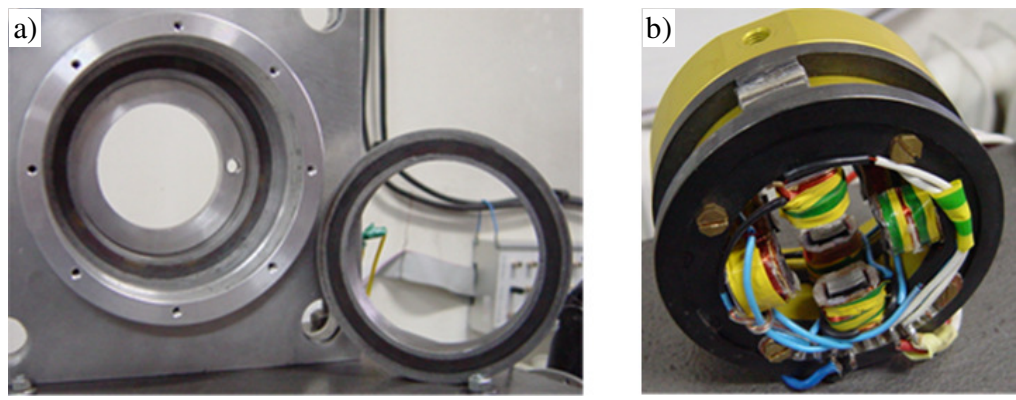

Rys. 2. Łożyska magnetyczne opracowane i wykonane w WAT: a) aktywne heteropolarne łożysko osiowe, b) aktywne heteropolarne łożysko promieniowe

Fig. 2. Magnetic suspensions developed and performed at the Military University of Technology: a) active heteropolar axial suspension, b) active heteropolar radial suspension

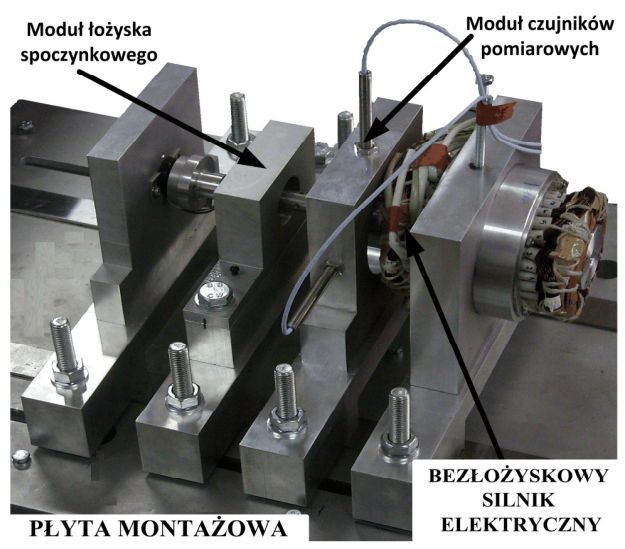

Rys. 3. Bezłożyskowy napęd elektryczny dla lotniczego układu wykonawczego

Fig. 3. Bearingless electric drive for aircraft execution system 
mi. Konstrukcja modelu laboratoryjnego silnika jest przedstawiona na rys. 4. Napędy tego typu w układzie bezżłobkowym są obecnie konstruowane na potrzeby projektu GABRIEL (Grant UE nr 284884), którego celem jest zbudowanie systemów startu i lądowania statków powietrznych. W ramach projektu PBS1/B6/7/2012 „Wykorzystanie nowych technologii inżynierii powierzchni i łożysk magnetycznych w budowie miniaturowego turbinowego silnika odrzutowego" jest opracowywany system łożyskowania magnetycznego dla silnika odrzutowego. Dodatkowo są prowadzone prace nad modelowaniem silnika, przygotowaniem i konfigurowaniem systemów akwizycji oraz elementami automatyzacji.

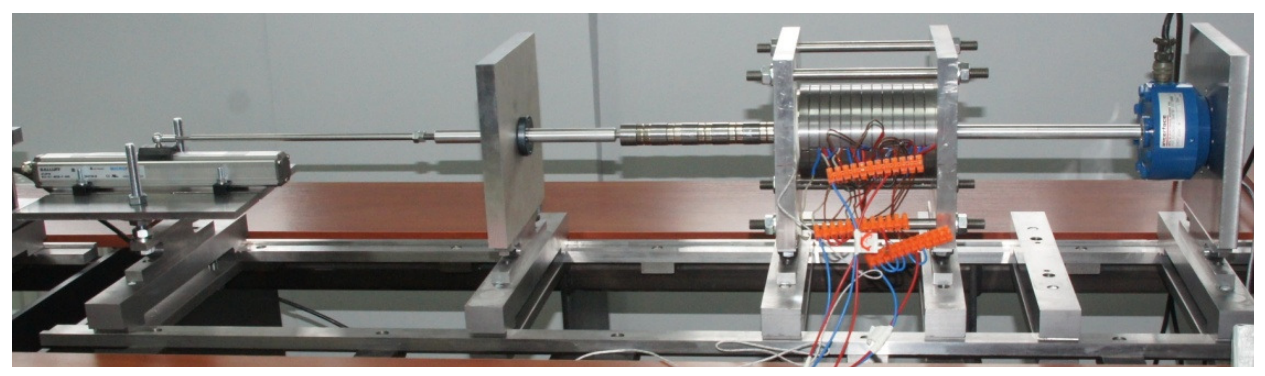

Rys. 4. Liniowy układ wykonawczy z napędem liniowym na stanowisku laboratoryjnym w konfiguracji do badania właściwości statycznych

Fig. 4. Linear execution system with the linear motor on the laboratory stand in the configuration for testing of static properties

\section{Infrastruktura pracowni}

W ramach realizowanego projektu przygotowano wyposażenie i infrastrukturę pracowni do:

- projektowania wysoko sprawnych zasilaczy i systemów elektroenergetycznych na potrzeby systemów sterowania aktywnego,

- projektowania zaawansowanych systemów sterowania,

- projektowania obwodów elektromagnetycznych układów wykonawczych,

- integracji i testowania systemów zawieszeń magnetycznych.

Pracownia jest wyposażona w stanowiska umożliwiające wyznaczanie charakterystyk statycznych i dynamicznych aktywnych zawieszeń magnetycznych (rys. 5.). Każde stanowisko składa się ze stabilnej ramy dostosowanej do obciążenia o wartości $600 \mathrm{~kg}$. Na ramie można zbudować linię wirnika o długości do $5 \mathrm{~m}$. Poszczególne elementy, takie jak czujniki, napęd, łożyska osiowe i promieniowe, są mocowane do uniwersalnych podpór. Dodatkowo przygotowano specjalistyczny osprzęt, który umożliwia pomiar sił osiowych i promieniowych w funkcji położenia wirnika i prądów płynących w uzwojeniach maszyny elek- 
trycznej. Dokładność ustawienia wirnika wynosi do $1 \mu \mathrm{m}$, a ugięcie wirnika $5 \mu \mathrm{m}$ przy maksymalnym zakresie pomiarowym czujników siły. Całość stanowisk dopełniają systemy akwizycji i rejestracji parametrów. W pracowni do rejestracji i archiwizacji są wykorzystywane systemy firmy National Instruments oraz dSpace. Pomiary mogą być realizowane w czasie rzeczywistym z wykorzystaniem systemu PXI i CRIO. Dodatkowo stanowiska są wyposażone w sprzęt i oprogramowanie, co umożliwia szybkie prototypowanie i testowanie cyfrowych układów sterowania pracujących w czasie rzeczywistym.
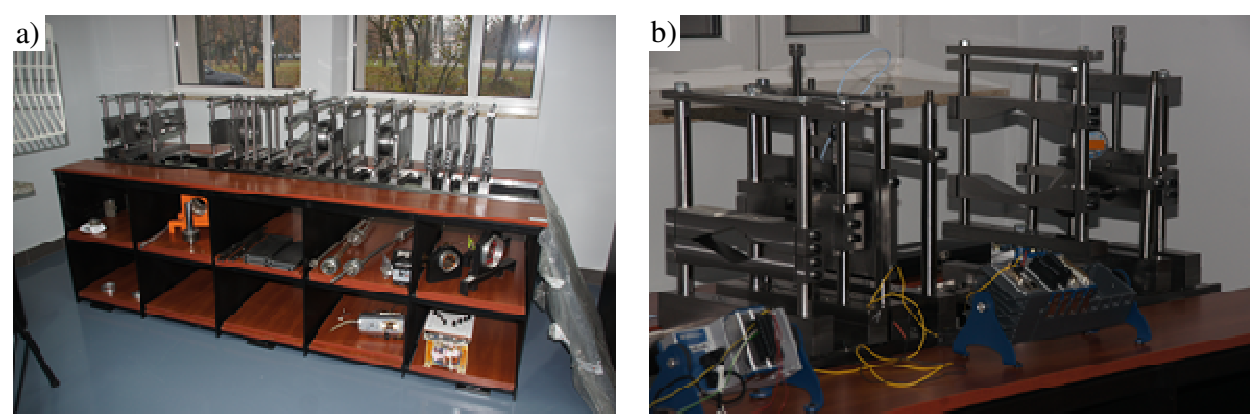

Rys. 5. Stanowisko do pomiaru charakterystyk statycznych (a) i dynamicznych (b) zawieszeń magnetycznych

Fig. 5. The stand for measuring the static (a) and dynamic (b) properties of magnetic suspensions

Pracownia zawieszeń magnetycznych jest również wyposażona w oprogramowanie przeznaczone do tego typu zadań. Podstawowe zadania projektowe, testowe i weryfikacyjne są wykonywane w środowisku Matlab-Simulink oraz LabView. W zakresie komputerowego wspomagania projektowania pracownia jest wyposażona w oprogramowanie do projektowania elementów mechanicznych, elektrycznych, elektronicznych, elektromagnetycznych i magnetycznych. Podstawowe programy wykorzystywane w pracowni to: AutoDesk Inventor, Altium Designer, MultiSim, Comsol Multiphysics, ISE Xilinx, Opera, LabView, Matlab-Simulink. Posiadane oprogramowanie umożliwia wymianę danych między poszczególnymi środowiskami i ich integrację $\mathrm{w}$ ramach projektowania złożonych systemów mechatronicznych. Przykładem takiego podejścia są łożyska magnetyczne, w których procesie projektowania można wyróżnić następujące fazy:

1. Wstępne obliczenia projektowe - najczęściej wykonywane w środowisku programu Matlab z wykorzystaniem języka skryptowego.

2. Wykonanie geometrii 2D i 3D z uwzględnieniem ograniczeń technologicznych w programie AutoDesk Inventor.

3. Wygenerowanie $\mathrm{z}$ wykorzystaniem Live Link for Inventor modeli niezbędnych do analiz metodą elementów skończonych w środowisku Comsol Multiphysics. 
4. Wykonanie analiz statycznych i dynamicznych metodą elementów skończonych.

5. Wygenerowanie w środowisku Comsol Multiphysics z wykorzystaniem Live Link for Matlab m-plików, które są wykorzystywane do symulacji dynamicznych w środowisku Matlab-Simulink.

6. Wykorzystanie procedur środowiska Matlab w programie Comsol Multiphysics do automatyzacji i przyspieszenia obliczeń.

7. Szybkie prototypowanie w środowisku Matlab-Simulink i LabView układów i praw sterowania oraz integracja zawansowanych praw z wykorzystaniem MathScript w LabView.

8. Wsparcie otrzymanych wyników przez analizy w środowisku NI MultiSim i jego integracja z LabView.

9. Wykonanie prototypów układów elektroenergetycznych i ich testowanie w środowisku NI MultiSim i Altium Designer.

10. Integracja i wykonanie testów z wykorzystaniem programów NI MultiSim, LabView, Matlab i Comsol Multiphysics (dołączenie modeli elektrycznych zasilania „modele 1D” do symulacji wykonanych w Comsol Multiphysics).
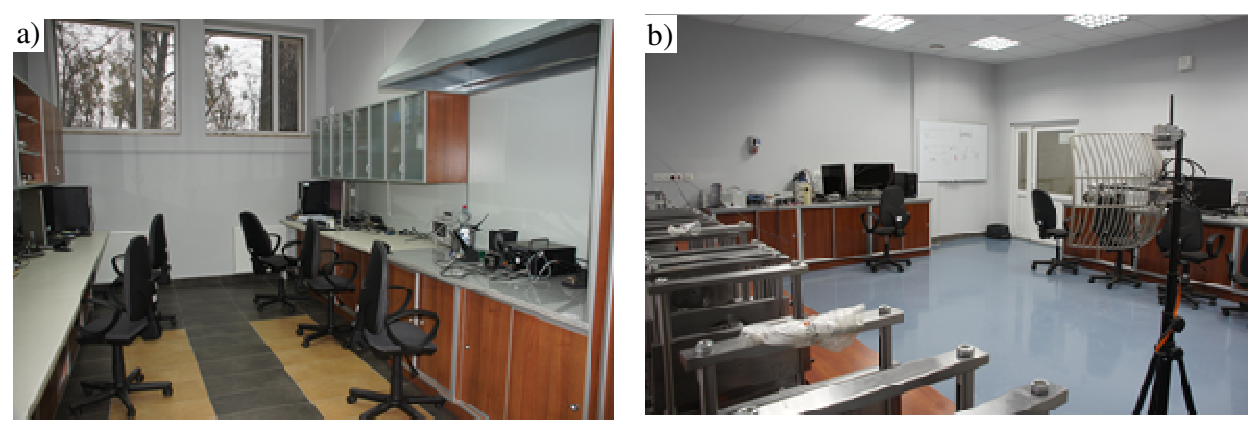

Rys. 6. Pracownia optymalizacji obwodów magnetycznych (a) oraz pracownia sterowania i pomiarów (b)

Fig. 6. Magnetic circuit optimization workshop (a) and the workrshop of control and measurements (b)

Wybór oprogramowania nie jest przypadkowy i ukierunkowany na głęboką integrację na potrzeby szybkiego projektowania zawansowanych systemów mechatronicznych. Pracowania jest również wyposażona w inną aparaturę naukowo-badawczą czołowych producentów, obejmującą:

- czujniki do pomiaru wielkości mechanicznych (parametry ruchu),

- przyrządy do pomiaru i rejestracji parametrów elektrycznych (mierniki, oscyloskopy, mostki pomiarowe RLC/M),

- pomiar wielkości magnetycznych (dwu-, trójosiowe sondy dla gaussomierza), 
- generowanie sygnałów i zasilacze,

- przetwarzanie sygnałów,

- specjalistyczny sprzęt programowalny z wykorzystaniem systemów czasu rzeczywistego i układów FPGA.

Do wykonywania tak złożonych zadań została przygotowana odpowiednia infrastruktura. Na zdjęciach są przedstawione pomieszczenia pracowni wzmacniaczy aktywnych łożysk magnetycznych, optymalizacji obwodów magnetycznych oraz sterowania i pomiarów (rys. 6.).

\section{Podsumowanie}

Pracownia zawieszeń magnetycznych jest przeznaczona do prowadzenia badań mających na celu wdrażanie technologii zawieszeń magnetycznych w technice lotniczej i kosmicznej. Przez realizację projektu POIG.02.02.00-14-022/09 zbudowano odpowiednią infrastrukturę, zakupiono aparaturę naukowo-badawczą i oprogramowanie. Dzięki temu utworzono unikatową w Unii Europejskiej placówkę przygotowaną do prowadzenia prac z zakresu aktywnych zawieszeń magnetycznych. Ponadto zespół naukowy posiada umiejętności realizacji zadań i jest gotowy do ich podjęcia. Przejawia się to zainteresowaniem placówek naukowych z kraju i Unii Europejskiej prowadzonymi badaniami w WAT w omawianym zakresie. Ponadto zespół badawczy w ramach pracowni jest gotowy do podjęcia innych zadań związanych z wyposażeniem awionicznym, automatyką, sterowaniem i mechatroniką lotniczą. O takich możliwościach świadczą realizowane przez zespół badawczy projekty bezpilotowych aparatów latających typu Quadrotor, głowic obserwacyjnych oraz sterowania takimi obiektami.

\section{Literatura}

[1] Henzel M., Żokowski M., Olejnik A.: The new construction of actuators for More Electric Aircraft. 6th Int. Conf. Mechatronic Systems and Materials MSM, Opole 2010.

[2] Raport z pracy badawczej własnej nr O N509 032736.

[3] Gosiewski Z., Falkowski K.: Wielofunkcyjne łożyska magnetyczne. Monografia Instytutu Lotnictwa nr 19, Warszawa 2003.

[4] Falkowski K., Henzel M.: High efficiency radial passive magnetic bearing, in Solid State Phenomena. Mechatronic Systems and Materials: Mechatronic Systems and Robotics. Trans Tech Publications 2010, 360-365.

[5] Henzel M., Falkowski K., Żokowski M.: The analysis of the control system for the bearingless induction electric motor. J. Vibroeng., 14 (2012), 1392-8716. 


\title{
POSSIBILITY OF MAGNETIC SUSPENSIONS INVESTIGATIONS IN AIRCRAFT PROPULSION RESEARCH LABORATORY OF MILITARY UNIVERSITY OF TECHNOLOGY
}

\begin{abstract}
A bstract
In the paper the Aircraft Propulsion Research Laboratory at the Military University of Technology is presented which is supported by the "Innovative Economy" Operational Programme, project no. POIG.02.02.00-14-022/09. In thta laboratory e.g. the Magnetic Suspension Workroom has been established. Where the unique in Poland and European Union research investigations under passive and active magnetic suspensions, their optimization, control, supplying, etc. are realized. Due to really good functional properties of magnetic suspensions operating at very low temperatures and high vacuum, for example, such solutions are widely applied in the space technology. Nowadays, the dynamic expansion of magnetic levitation systems and their systematic utilization in different applications. The laboratory will find solutions of problems concerned with aircraft drives and its operating. It makes possible modernize investigated constructions and also to design the new one.
\end{abstract}

Keywords: magnetic suspensions, aircraft propulsion, optimization, control

DOI:10.7862/rm.2013.29

Otrzymano/received: 15.09 .2013

Zaakceptowano/accepted: 22.10 .2013 